\title{
VI.-DISCUSSION.
}

\section{FEELING AND EMOTION.}

\section{By H. M. Stantey.}

As Prof. Wundt well remarks, the chapter on the Feelings is one of the darkest in the history of psychology, and Dr. Nahlowsky speaks of the feelings as a world the entrance to which is as dark as that of the Hades of old. Prof. Wundt gives three divisions of psychologists with respect to their treatment of the feelings: first are those who have treated feeling as the deepest ectivity of the cognitive feculty; second, those who make feeling depend on "interaction of presentations"; third, those who emphasise feeling as subjective complement of "objective sensations and representations". The fundamental distinction is, however, deeper than these distinctions with reference to the relation of knowledge and feeling; it is that of spiritual and physiological treatment.

Psychologists as a whole are divided into the two schools, physiological and spiritaal, and the treatment of the feelings varies most manifestly between them. The one school emphesises the objective side, the other the subjective. The physiological school relates all feelings, higher and lower, to the organism; while the spiritualistic school connects the lower feelings with the organism, but the higher, as love of truth, \&c., ere related only to the spiritual nature. With the physiological school, feelings are merely the subjective side of objective changes, are determined by the objective; with the spiritual school, subjectivity perceives and determines objectivity. With the physiological school there is a hard and fast pre-established harmony of subjective and objective changes, but the subjective face is incidental concomitant or function of the objective; with the spiritual school, all is ideal and subjective, or at least the subjective moulds the objective and expresses itself in the material.

What is the nature of an emotion? Most psychologists are content to simply refer us to our own conscious experience, as Messas. Bain, Allen and Thompson. Mr. Spencer seeks to go deeper. All states of consciousness are divided by him into feelings and relations between feelings, which last mean, of course, as he admits, relational feelings. Every state of conscionsness is sush by virtue of its having a relational or cognitive element. Some stites are more relational than others, but none are absolutely non-relational ; thus the sense of smell is less relational than that of sight, but still to some extent relational. Every feeling is thus feeling of something and has cognitive velue. The non-relational element is feeling proper, and may be sensa- 
tion-peripherally initiated, or emotion-centrally initiated. This physiological definition does not clear up the psychological natare of emotion. Mr. Spencer mixes up physiological and psychological classifications. After dividing physically into peripherally and centrally initiated, he then divides these transversely into actual and ideal, or vivid and faint, or presentative and representative. If mind be built up, after the Humist fashion, of impressions and ideas, it is evident that the fundamental psychological division is this into presentative and representative (at any power). The emotions belong to the latter class.

We are now led to ask, What is the essence of feeling as such, whether emotion or sensation? What makes feeling, feeling? and the answer is, as we have seen, the negative distinction of non-relational. If with Hamilton and $\mathrm{Mr}$. Spencer we emphasise the natare of feeling as subjective and non-relational, it seems evident that the growth of mind has been from an almost complete subjectivity of feeling to a very considerable degree of objectivity in perception. We may believe with $\mathrm{Mr}$. Spencer in the subject-object nature of all consciousness, and yet insist on this law of the growth of mind, which is, perhaps, noticed by $\mathrm{Mr}$. Spencer only indirectly in his discussion of correspondence. In the lowest forms of consciousness, as seen in low forms of animal life, consciousness is, no doubt, maximum of subject and minimurn of object. There is probably but little localisation of feeling, pain and pleasure being mostly organic. The externality of its body is but vaguely known, if known at all, and externality beyond is not recognised. We view our hands as in a measure external; the lowest animal feels its body as itself, does not in proper sense perceive its body. Its consciousness is, as it were, part and parcel of matter, and it is only in higher forms that consciousness rises to a perception, to a knowledge of itself over against object. In the progress of mind feeling decresses, cognition increases, till, as in scientific human eyesight, perception becomes almost pure from feeling.

$\mathrm{Mr}$. Spencer is inclined to believe that each state of consciousness as subject-object relation is compounded of the feeling and the relational element, knowing; but it seems rather more probable that in the final analysis feeling and knowing are to be considered as closely consecutive states, feeling being precedent in the order of evolution. The subjective is first wakened-first feeling, then knowing. The esrliest stages of psychical life in the young of the human species and higher animals is almost purely organic sensation, perception rising later, and we judge that the history of the individual is indicative of the history of the race. At least we may say this, that the earliest psychical life is prevailingly that of feeling, because perception, if it in any true sense occurs, is speedily obscured by feeling leading to the action demanded in the struggle for life. The necessary immediacy of reaction in presence of environment in early life is secured only through 
feeling as stimulating will. Feeling, as the egoistic, personal and subjective determination of mind, must increase according to law of self-preservation; but, while the subjective bearing must always be kept in mind by the element of feeling, still the lew seems to be-that immediate personal reaction, impulsiveness, is relatively unsuccessful, and the objective side of mind, the intellectual, tells most in the conflict of life, though this becomes useful only throngh the element of feeling. Feeling in the progress of mind then takes up less and less space and time in consciousness, and the objective relational element more and more space and time; but feeling always remains as deep and determining factor. The evolution of intense personalities can only be through subjectiveness of feeling. Dr. Nehlowsky, while emphasising feeling as subjective and knowledge as objective elements, would make will subjective-objective element of mind. But it is evident that will and feeling belong together as subjective. Will is subjectiveobjective only as it is teleological, or involves knowledge; but this is true of most determinations of developed consciousnesswhether volitions or emotions.

We cannot then, perhaps, reach a deeper analysis than thisto consider feeling as subjective element in consciousness; but we may inquire in what form feeling is primitive. Pleasure and pain have been considered primitive by many psychologists, and all feeling may be considered as developed pleasure and pain. Mr. Spencer views pleasure and pain as concomitants of emotions, and not the emotions themselves. But it seems more correct to regard pleasure and pain as primitive and fundamental feeling, out of which through differentiation by knowledge proceed all feelings. Psychical life in its lowest forms seems to be mainly pleasure and pain simply as such, without perception of the pleasurable and painful. There is merely pleasure and pain, and not the pleasurable and painful. Pleasure and pain appear in all feeling, and, as far as there is subjective reference, throughout all. mental life, although often almost hidden in consciousness. There is, indeed, mathematically considered, an indifferencepoint where pleasure and pain meet, but psychologically considered every state of consciousness is to be characterised as pleasurable or painful. Feelings may be apparently and in the popular sense of the word indifferent, but never so psychologically and scientifically indifferent as Prof. Bain claims. Careful analysis will, we think, show that absolute indifference is nowhere to be found in consciousness. The subject always hes a certain tone, which, whether distinctly recognised or not, remains as an essential element of consciousness. That pleasure and pain seem concomitant to emotions, arises from the fact that most, if not all, the feelings in developed consciousness, to which we naturally refer, are very complex. Anger, so far as it is feeling, is pain, to which is added the will-element of hostility and a quite distinct perception of object of the anger. How much know- 
ledge enters into our common conception of emotion is negatively evident from the phrase 'blinded by passion' which is applied to one who has almost lost the relational element from consciousness. Emotions in the higher stages are filled out by knowledge and will, but if we extract the pure feeling from any given emotion, we can have as mere subjectivity only pleasure and pain. When objects come clearly before the mind, the accompanying pain or plessure is recognised in memory as coloured by the object, by knowledge. We feel pain differently through perception by eye and ear; but where there is no eye or ear, distinctions of this kind must disappear. And so we recognise that psychical life is at bottom and in its earliest forms simply pleasure and pain with little or no differentiation from objects. Developed psychical life perceives, feels, wills; undeveloped psychical life feels, wills, perceives. The unfeeling stone is not roused to self-preservation by feeling, it passively endures its fate. The animal, however, through feeling reacts by locomotion or self-defence and preserves itself. Thus by virtue of feeling there exist in nature active beings which have a worth of being in themselves.

Feeling then, we conclude, is the purely subjective factor in consciousness; and per se, both as developed and undeveloped, is merely pleasure and pain. The older psychologists, as Spinoza and Leibniz, were inclined to view the feelings as inadequate or confused ideas. This view was easily suggested by the fact that in intense subjectivity of feeling perception is obscured, bat this does not help us to any clear conception of the natare of feeling, which is best gained through studying the history of mind. We will now consider some espects of the perplexing subject of Emotion and its expression.

Theories of expression are plainly divisible according to the method of treatment by spiritual and physiological schools respectively, according as the relation of mind to body is regarded as initiative, or as concomitant or resultant. Expression in literal significance, according to common opinion, and as urged by the spiritual school, is subsequent on, and determined by, emotional consciousness. It is the bodily expression of mentel action. With the other school the physiological factors are the determining ones. Descartes viewed the passions as reactions from the body. Expression is connected with physical support by Prof. Bain. Prof. James makes feelings reflexive movements in consciousness due to the so-celled expressions. Hamilton makes feelings of pleasure and pain reflexive, not only, however, of impeded or unimpeded bodily movements, but also and primarily of impeded and unimpeded conscious activities, and he belongs then rather to the spiritual school. Mr. Grant Allen has extended the physiological explanation to the feeling of beauty, and intimates that all the higher feelings have their true philosophy in this point of view. Prof. Wundt views feelings as reactions from sensation. 
Prof. James's theory (MIND XXXIV. 188) is that expressions, instead of being determined by the emotions, determine them. We do not strike becanse we are angry, but we are angry because we strike. This involves the general theory that body not mind is determining factor; that emotions, \&c., are merely subjective side of objective changes. The opposite theory is that the expressions, neural changes, \&c., are but objective side of subjective changes, e.g., of emotions. From the point of view of conscionsness we speak of expressing our emotions, but from the real point of view, according to Prof. James's theory, we should speak of emotions being expressions in consciousness of our bodily activities. This is a thorough and logical carrying out of the physiological point of view, which should emphasise not only nervestates as objective support of conscious states, but also muscular and organic states. Mind as series of subjective changes finds its objective support in body as a whole, and not in nerves merely. To consider this general attitude of thought would call for too extended discussion. It is sufficiently evident that, epprosching from the objective physiological side, this treatment of emotion as concomitant and resultant of not only neural bat general bodily activities, known from the psychological point of view as expression, is inevitable. Let as notice this position, however, from the point of view of conscionsness.

Prof. James points to the fact that exercising the expressions or imagining the feeling calls up the feeling, as a proof of his theory. This, however, is merely a matter of association, and can prove neither a real precedent nor resultant. We may call up ideation as well as emotion by producing associated activities. In the interdependence of the conscious life, emotion, perception and willing call up each other without reference to causative order. Any one element of conscionsness may be regarded either as resultant or stimulant according as we look at preceding or following state of consciousness. In the order of evolution, pain and pleasure arise from certain actions to inhibit or stimulate repetition of actions. Feeling is then both resultant and stimulant. The emotions may arise from the expressions by association, but the original dependence is that of expression on emotion. The further test, that we cannot imagine an emotion without bringing in bodily presentation, is simply a necessity of imagination as such, and due to association and organisation.

In common language emotion is made precedent to expression, and this is the psychological standpoint. We speak continually of venting anger, giving expression to feeling, giving way to our emotions, \&c. The will represses, expresses or impresses emotions. When the bodily expression is not allowed there is rankling, when repressed thoughtfully and measurably there is repression, of emotion; when expression is allowed in measure there is relief, when expression is uncontrollable there is exhaustion; when an emotion is desired, the will by repeating known 
expressions may impress emotion into its forms. Bimulating expression is the actor's art; but when the simulation is forgotten by either actor or andience, nature appears and art disappears. Bimulation of expression leads easily to feeling and to natural expression by the principle of association. Emotion may then be directly stimulated or repressed, or indirectly through expression. Excitement may be stopped by mental measures or by deep inhalations. Expression may be expressive to the individual and not to others, for example, when the heart jumps into the throst; to others and not to the individual, as very often in the knitting of the brow ; to both, as in gesture.

Darwin relates emotions to expression by three principles : first, principle of survival, or as he terms it, " servicesble associated habits" ; second. principle of antithesis ; third, principle of direct action of nervous system. The evolutionary principle of survival bids fair to be a very importent factor in explaining expressions. According to this principle we seek to explain many expressions by studying their history, and many expressions are then found to be what we may term degraded actions. When feeling arises, the old associated actions, now disused, tend to follow as survival in degraded form. The running from feared object was for self-preservation, and this running, of course, accelerated the action of the heart and connected organs, with depression of more remote organs. The throbbing of heart, \&c., as expression of fear, are then survivals of the running of generations of ancestors. We may remark in this connexion that expression as partial may act in accumulatory manner, as when in fear there is throbbing of the heart, which acts, not in serving the limbs as originally, but in adding to mental excitement. Sufficient attention has not, perhaps, been paid to what we may term the negative or passive expressions which are due to excessive withdrawal of blood from certain organs by other organs for active expression. Emotions in any high degree elmost always enhance some function to the depression of others. Just why there should be the particular depression, must be determined by physiological research. Pallor from fear may be regarded as a negative expression. Darwin enumerates as unexplained expressions, "change of colour in the hair from extreme terror or grief-the cold sweat and the trembling of the muscles from fear - the modified secretions of the intestinal canal-and the failure of certain glands to act". (Expression of the Emotions, 350 ; but cp. 81.) It may be that some or all of these are negative or secondary expressions, due to abnormal lowering of certain functions through abnormal heightening of other functions in primary and positive expression. It seems to us at any rate that this distinction of positive and negative expressions is worthy to be made and may be usefal.

If many expressions of emotion are degraded actions in survival, it is plain that the emotion cannot be the reflex of the 
expression. The expression, on the other hand, is the reflex or result of the emotion; it is the survival of the associated past actions which were originally consequent on a given emotion. This law of survivel accounts for much that Prof James seeks to account for by his theory; it gives account of the expressions not as causative, but as identifying them with common actions. To be consistent then, Prof. James must make all actions determine emotions, since expressions are reduced to actions. $\mathrm{His}$ theory is the reverse of $\mathrm{Mr}$. Spencer's by making emotions peripherally not centrally initiated.

This leads us naturally to consider Darwin's third law, the principle of superfluous energy issuing in expressive actions, which is also insisted on by Prof. Bain and Mr. Spencer. If expressions are resolved into actions, the law of action, efflux of energy, is the law of expression. If actions be viewed as centrally initiated, we know that there must be accumalation of nervons energy sufficient to discharge itself along muscles, \&c. Nervous energy, as the concomitant of mental excitement, will, says Mr. Spencer, discharge itself along lines of least resistance, along the smaller muscles and those most habitually used. From the latter law arise what we may term individual expressions, doe to the habits of the individual; for example, ander slight nervous tension one man will move his legs, another his arms. Emotions then lead often unconsciously and in a motiveless manner to usual activities. The term 'expression' had best, we think, be distinguished from action in the proper sense. A man may be walking fast from excitement, and the walking would then be called an expression; but the ranning of a man to catch a train would hardly be called an expression. Teleological action is then set off from expression. But unteleological action cannot always be termed expression, so far as it is merely instinctive, and not indicative of conscious life at all. Expression is an indefinite region between instinctive and teleological action ; it is action, but degraded action of the survival or habitual type.

Darwin's second principle, that of antithesis, is in reality not a principle, but a fact. We act in expressing emotion in opposite ways, not because the ways are opposite, but inevitably from opposite stimuli. It is merely a natural fact that opposite emotions find opposite expressions. A principle of likeness would on the same basis be required, but this like that of antithesis is a fact, not a principle.

Prof. Bain insists upon three principles of expression-spontaneity, diffusion, and pleasure and pain. Spontaneity is to be taken into account by way of subtraction from expression. A man in delirium manifests a great variety of movements which are not expressive, because there is nothing to express. In the play of children there is overflow of nervous energy into natural channels, but the movements are not properly expressive. Prof. Bain maintains that in joy, for instance, this element must be 
subtracted in order to gain the amount of resl expression. It may be necessary to subtract on the principle of spontaneity, but not we think es unexpressive. Play is expressive of the emotion of high spirits, and is to be subtracted from the expression of joy with which it is often associated. Sponteneity is not a principle then of the relation of expression to emotion, unless it be called a principle that various emotions and expressions are often very closely associated, and the value of each must be determined by analysis and by the subtraction of the others.

The principle of diffusion is the principle of surplus of nervous force which is insisted on by Darwin and Mr. Spencer. The principle of pleasure as the enhancement of function, and pain as the depression of function, Prof. Bain declares to be fundamental in determining expression. He opposes $\mathrm{Mr}$. Spencer's law that intensity of expression is as intensity of feeling, by modifying the word feeling with the word pleasurable. That the character of the feeling as pleasurable or painful should affect very deeply the character of the expression is to be expected according to evolution. Pain will produce contractive, defensive, remedial measures; pleasure, expansive measures. This is implied in the view of expression as degraded action. Again, actions following from pains or from pleasures would be antithetical; and thus Darwin's principle of antithesis is easily placed by Prof. Bain. That which injures the organism produces pain, but this pain is reflex from the organism, and the functional derangement is cause, not expression, of feeling. Now actions are put forth upon the stimulus of this painful feeling, and these actions may become expressions. This functional depression, causative of the feeling, is, perhaps, confounded by Prof. Bain with expression. Pain is accompanied by functional derangement-not necessarily depression, as Prof. Bain emphasises-in the part from which pain arises, but this is not to be confounded with expression proper. Pain is often stimulant to the organisin as a whole, lifts the tone of the organism, as in the cut of a whip, although there be derangement in single part at the skin. The painful feeling and the pleasurable alike express themselves by intensity, local or general, not by depression, for only thus can there be positive and hence negative expression. There must be an arousing of nervons energy in order to any expression. Thus Mr. Spencer's law is applicable. The general law of expression is simply that conscious state as feeling is stimulant and directive of action whether the feeling be pleasurable or painful.

Prof. Bain tends to look upon expression, not as we have treated it, as consequent of conscious state, but as " incidental to physical support" (Senzes and Intellect, p. 704). But physical support as basis of conscious states is to be carefully distinguished from expression. Feeling, as conscious state, has a physical substratum and it has an expression. The expression is properly that action which 
has been, is, or may be under the control of the will. The angry man may be angry and restrain expression, but, as long as he is angry, there will be a certain physical substraturn of the mood, a certain state of the nerves and of the cerebral circulation.

We sball notice in conclusion the subject of the Classification of the Emotions. The feelings-and we have used the term emotions as in general synonymous - have been most variously divided. Spinoza in the Ethica develops a classification from the primary feelings, pleasure, pain and desire, through moditication by the inadequate, the rational and the intuitive ideas. Hamilton grounds his divisions of the feelings on his divisions of the other powers of the mind, for feeling is with him mere adjunct of other powers, contemplative and practical. Dr. Nahlowsky divides into simple and complex, and also into active and passive. Mr. Spencer divides variously, "as central or peripheral, as strong or weak, as vague or definite, as coherent or incoherent, as real or ideal" (Psych. i. 272). He adds agreeable and disagreeable feelings; and works out the distinction of real and ideal into presentative, presentative-representative, representative, re-representative. This purely psychological classification gives the order of evolution of feelings in a very general way, but Mr. Spencer enters upon no detailed examination of the feelings. Prof Bain claims to be in substantial agreement with $\mathrm{Mr}$. Spencer, but his eleven genera appear rather heterogeneous and only in a vague way evolutionary. Mr. Spencer (Essays, ii. 120) approves of Prof. Bain's ides of a natural-history classification, but points out that Prof. Bain has not worked out the ideal, giving merely a "descriptive psychology": a true evolutionary classification should be founded on study of "the evolution of the emotions up through the various grades of the animal kingdom," study of "the emotional differences between the lower and higher human races," and lastly, by observing "the order in which the emotions unfold during the progress from infancy to maturity". It is much to be regretted, however, that Mr. Spencer has not taken up the emotions in detail. $\mathrm{He}$ has given us mere rough divisions, not a classification.

Mr. Mercier's classification, as worked out in MiND XXXV.-VII., is very elaborately and carefully done. He gives a more thorough natural-history classification than any which has yet been set forth, giving classes, sub-classes, orders and genera. Many of the Tables are very ably worked out, but it would not be hard to criticise. Table iii. is particularly suggestive, but it may be doubted whether certain of the feelings, as Courage and Sense of Victory, always have relation to self-conservation. Again many higher and late developed feelings creep into the earlier Tables, as Resignation and Meekness into Table ii., which is somewhat like putting the cat among the radiates. We, of course, recognise that late forms may belong to early types, but this will not 
account for such instances as these. In Table ii. the grand division is according to agent and event, but in low forms of psychical life there is no such thing as event-all is animate. In this and other Tables it is evident that Mr. Mercier has taken on the whole a statical rather than an evolutionary point of view. The classification is primarily logical and descriptive rather than genetic. Again feelings which are nearly akin in essence and expression are separated; as, for example, it is to be doubted whether Terror, Horror and Dread should be respectively assigned to different genere.

It may be a question how far a natural-history classification can be applied to psychological matters. If it be the true method, we must apply it throughout to all forms of consciousness, and if, as we have contended, feeling as feeling is only pain and pleasure, is pure subjectivity, but is differentiated through knowledge and will, then the classification of the emotions is dependent on the classification of the cognitions and the volitions. We are not inclined to accept Hamilton's classification formed on this principle, because it is not evolutionary. Knowledge is mingled with most of the feelings as treated by $\mathrm{Mr}$. Mercier, and his method of classifying by object of feelings emphasises this; but, however valuable and suggestive, his classification remains faulty in content, method and form. It is faulty in content primarily becanse it does not have regard to psychological classification as \& whole, without considering which it is as impossible to come at satisfactory results as if we should attempt to classify vertebrates by themselves. As all animals constitute a kingdom, the whole of which must be kept in mind by the classifier, so states of consciousness constitute such a whole, such a unit, that the classifier must attack all psychological states in order to form a satisfactory classification of any one group, as emotion. The method also does not make sufficient use of comparative psychology. The nearest approach to a truly evolutionary form in classification is, perhaps, that modification of Prof. Huxley's, which Mr. Spencer sketches in his Biology. Mr. Mercier's classification, as it lies, is linear, but the Tables, the author insists, must be combined in imaginetion into a tree-like form. Just what this form is, it is rather difficult to carry in mind, and it is in be hoped that Mr. Mercier will sketch it out in full.

We may illustrate roughly our notion of what a classification of the Emotions might be in this manner.

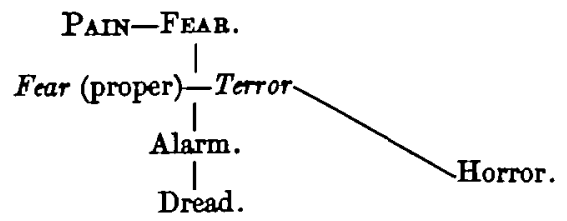


It has been arged that pleasure and pain make up feeling as feeling. The frst differentiation of Pain is through cognition of object painful. This state is Fear. Difference in intensity is developed very early, so we have Terror and Fear proper. Cognition of time soon differentiates-under immediate form as Alarm and under more distant form as Dread. Far later Horror as altruistic form of terror will arise. We merely give this as an approximate illustration of the correct form and method of evolutionary classification. The development of mind as a whole must be followed. Pleasures and Pains would appear as the two great correlated classes into which the emotions would divide, and each would in interdependence be differentiated by the forms of cognition and volition as these severally arise.

\section{MR. MERCIER'S CLASSIFICATION OF FEELINGS}

\section{By Carveth Read.}

A plan of classifying the Emotions, or rather of providing a substitute for such a classification, had occupied me for some time, when there appeared in MIND a series of remarkable and in many ways admirable articles on the Classification of Feelings by Mr. Mercier : articles of such excellence that it would have been absurd to proceed with what I had to say without some examination of them. And whilst the publication of my own notions is still unavoidably postponed, it seems best to print at once the following controversial matter. Mr. Mercier begins by professing a general adherence to Mr. Spencer's psychology, and to the principle of Evolution; bat, finding some fault with that philosopher's classification of Feelings, he proposes to set forth another more in accordance with the rest of the system. The objections he raises against Mr. Spencer's doctrine as exponnded in Pyychaloryy, \& 480, must be allowed, I think, to have some foundation in the text. He shows that the same feeling, Terror, may be classed as Presentative-representative, Representative, or Re-representative; and that feelings so different as Blueness and Triumph seem to be sometimes included in one class (Mind XXXV. 326-8). Confining attention to $\$ 480$, these objections seem pertinent; but this leads me to make three remarks. First, Mr. Spencer in classifying feelings has not resorted to as much abstraction as he might legitimately have done, but has rather dealt with total states of conscionsness. Thus Terror at sight of a snake, Terror at thonght of a snake, and Terror without definite accasion on going into the dark, seem, as Mr. Mercier points out, to be placed in three different classes. But surely the element of Terror is the same in all these cases; and, as to the ancient essential body of it, is in each case of the same degree 